\title{
MISTRAL MISTRAL
}

Journal of Latin American Women's

Intellectual \& Cultural History

\section{Los sueños del castillo: Peuma mestizo y sonoridades rebeldes para una infancia recluida}

Catalina Donoso Pinto, Universidad de Chile

Lorena Herrera Phillips, Universidad de Chile

To cite this article: Catalina Donoso Pinto y Lorena Herrera Phillips. 2021. "Los sueños del castillo: Peuma mestizo y sonoridades rebeldes para una infancia recluida." Mistral: Journal of Latin American Women's Intellectual \& Cultural History 1 (2): 84-99, https://doi.org/10.21827/mistral.2.38030

\begin{abstract}
This work analyzes the documentary Los sueños del castillo (2018) by Chilean filmmaker René Ballesteros, which depicts the daily life of a group of children confined in a state institution for having committed crimes. The documentary focuses on the stories about their dreams that the youths tell each other and the filming crew. It is important that this detention center is located in a Mapuche territory, given the relevance this culture gives to dreams (peuma). Taking Kathryn Bond Stockton's notion of queer childhood as any defiance to normativity, we articulate a crucial relationship between institutional confinement as punishment for transgression, the interest in dream activity, the horror genre as the aesthetic chosen by the director, and the relevance given to sound throughout the film.
\end{abstract}

\section{Keywords}

Childhood; Dreams; Horror documentary; Sound landscape; Peuma

\section{Resumen}

El presente trabajo analiza el documental Los sueños del castillo (2018) del realizador chileno René Ballesteros, que retrata la vida de un grupo de niños en reclusión en una institución estatal por haber cometido delitos. El documental se centra en los relatos de los sueños que los jóvenes reclusos se narran unos a otros y al equipo realizador. Es importante para la película que el centro de detención esté situado en territorio mapuche, dada la relevancia que esa cultura da a los sueños (peuma). A partir de la noción de infancia queer como desafío de la normatividad, propuesta por Kathryn Bond Stockton, articulamos una relación entre la detención institucional como disciplinamiento de esa transgresión y la perspectiva del documental que trastoca esa coerción a partir del interés por la vida onírica, la elección del género del terror como opción estética en el documental y la relevancia dada en la película a la dimensión sonora.

\section{Palabras clave}

Infancia; Sueños; Documental de terror; Paisaje sonoro; Peuma 


\title{
Los sueños del castillo: Peuma mestizo y sonoridades rebeldes para una infancia recluida ${ }^{1}$
}

\author{
Catalina Donoso Pinto, Universidad de Chile \\ Lorena Herrera Phillips, Universidad de Chile
}

Según René Ballesteros, director del documental Los sueños del castillo, la idea de dar relevancia a la vida onírica de los jóvenes reclusos que protagonizan el film "es el pilar mismo del deseo de hacer la película" (conversación con el director vía correo electrónico, 2 de marzo de 2021). La información que obtuvo de parte de una colega psicóloga ${ }^{2}$ acerca de las pesadillas recurrentes que asediaban a los jóvenes de este centro de detención, además de la declaración de una machi que hacía un trabajo intercultural en el lugar sobre la construcción del edificio del centro encima de un cementerio ancestral mapuche, despertaron en Ballesteros el interés por abordar el documental de una manera no habitual, al reconocer en la historia un potencial vinculado al género del terror. Esta decisión es un primer desvío que hace aparecer una dimensión nueva a las vidas recluidas de los protagonistas y le permite al documental escapar de los lugares comunes que tantas veces limitan las posibilidades de lo decible. La figura del joven delincuente es un tópico que suele explotarse o bien desde el rechazo o desde la lástima. La configuración de las imágenes a partir de las narrativas de los sueños y de su potencial como relato asociado a un género ${ }^{3}$, abre una puerta hacia aquello inesperado, no predefinido, del objeto que intentamos conocer.

La aproximación a la idea de infancia queer que desarrollamos en este texto proviene de lo planteado por Kathryn Bond Stockton en su libro The Queer Child al desbordar la acepción más estricta que lo vincula a una infancia gay u homosexual y extrapolarlo a la infancia en general, por su carácter desviado e imprevisible: "a gay child illuminates the darkness of the child" (Bond Stockton 2009, 3), escribe la autora. Desde ese paradigma es que se atreve a cuestionar la idea de maduración o crecimiento como un movimiento hacia arriba (to grow up) para reivindicar el crecimiento en sus direcciones desordenadas y caóticas, un crecer oblicuo (growing sideways) que nos hemos permitido traducir libremente como "crecer chueco", 4 para enfatizar los caminos no pauteados que nuestra nunca finalizada maduración tiene como hoja de ruta. La infancia es queer en tanto es la inmadurez ofensiva hacia una cultura que no concibe la posibilidad de un eterno inconcluso.

La palabra infancia ha sido definida etimológicamente como la ausencia de voz, y desde ahí se ha construido culturalmente desde la ausencia de opinión, de

\footnotetext{
${ }^{1}$ Este artículo se enmarca en la realización del proyecto Fondecyt n 1191698 "Documento inestable: una propuesta de archivo performativo y subjetividad material"

${ }^{2}$ René Ballesteros es psicólogo de profesión y como tal había tenido experiencia trabajando en otros centros de detención pertenecientes al Servicio Nacional de Menores (SENAME) del estado chileno.

${ }^{3}$ En "El decir y lo dicho en el cine: ¿Hacia la decadencia de lo verosímil?”, Christian Metz expone de qué manera el cine debe enfrentarse a distintos aspectos que limitan su universo posible, dentro de los cuales ubica las fronteras de un verosímil dominante cuyo origen es siempre cultural y sus implicancias ideológicas. Una de las cuestiones que destaca respecto de los géneros es su capacidad para declarar el verosímil al que adscriben, no intentando naturalizarlo.

${ }^{4}$ Hay todavía discusión sobre el origen etimológico de la palabra, pero una de las versiones sostiene que proviene del mapudungun chulleco, que significa torcido.
} 
consideración ciudadana a la validez de un sujeto con ciertas características racionales. Sin embargo, es interesante problematizar si culturalmente la infancia ha tenido más que ver con un esfuerzo de negar un espacio de opinión y decisión a cierto tipo de personas, a causa de su supuesta ausencia de racionalidad, o si más bien esa etimología debiese pensarse como una otredad o desvío de la voz, más que como su falta. En Los sueños del castillo esto se presenta en una doble capa. En un primer encuentro nos enfrentamos a una infancia hablante, la infancia marginada del mapuche, del gitano, del que delinque, sujeto hablante que tiene permitido expresarse por las circunstancias específicas que lo llevaron a estar como está y, sobre todo, donde está. Pero ¿qué podemos encontrar bajo esa primera capa? Un cuestionamiento profundo a los límites de la racionalidad, de lo verosímil, una provocación al orden normado de la verdad; lo que podríamos llamar, más que un tejido, un entramado queer de una infancia doblemente torcida. Cuando recogemos la idea de un crecimiento no vertical que caracterizaría la cualidad queer de la infancia, no buscamos oponer a esa racionalidad un modo de ser irracional, sino que plantear la disolución de las oposiciones. "Crecer chueco" no es la contraparte de una maduración lineal y ordenada, sino la posibilidad de encontrar modos múltiples, no preconcebidos para ese crecimiento.

En este film encaramos precisamente la pregunta por las capas de esa otredad, no sólo se trata de infancia, se trata de infancia mapuche, rural, gitana, delincuente, marginal, que habita el margen, pero por fuera, no por dentro. Si nos permitimos pensar esta ausencia de voz más bien como una otra voz, como un desvío de la voz, como alteridad de la palabra y el silencio, la infancia y quienes habitan la infancia, de los modos más diversos, no se encuentran en una etapa determinada del "cronos", donde se les autoriza ser de cierto modo por la edad que tengan y por las leyes que recaen sobre aquello. Quienes habitan la infancia, esta voz desviada, quebrada, habitan la voz del gesto, la voz del pensamiento, vale decir una serie de imágenes -imaginaciónhuellas que juegan con la ausencia-presente de todo lo que el cogito cartesiano, el ratio de la razón, ha sabido bien marginar. La infancia habla desde el gesto de la otredad o es la otredad la que se manifiesta desde la infancia. Esto inquieta a la razón adultocéntrica que necesita organizar la progresión de los hechos hacia un fin seguro y determinado. ¿Por qué no duerme este niño? ¿Por qué sueña lo que sueña? ¿Lo debemos medicar para que pueda dormir sin soñar o soñar sin recordar? No es un problema propio de la razón, es un problema de la idea de un razonamiento recto y predeterminado lo que aquí nos importa cuestionar.

Jorge Larrosa en su texto "El rostro enigmático de la infancia", propone lo siguiente respecto de lo que el cine a veces logra develar de la infancia: "El cine nos abre los ojos, los coloca a la distancia justa y los pone en movimiento. A veces, hace eso enfocando el objetivo sobre los niños (...) Sobre su sumisión y sobre su indisciplina. Sobre sus palabras y sobre sus silencios. Sobre su libertad y sobre su abandono. Sobre su fragilidad y su fuerza. Sobre su inocencia y su perversión" (Larrosa 2007, 18).

Si dejamos de ver a la infancia como un momento de la vida, un comienzo e intentamos verla desde el gesto, como voz-lenguaje-quebrado-desviado, podríamos centrarnos en ella más desde una trama de significantes que no se reducen sólo a significados. De este modo podríamos pensar a la infancia como el territorio de una lengua siempre extranjera, que sacude la propia lengua, sea cual sea. Así, esta voz otra, esta lengua extranjera, es una que se sale de los márgenes, que se desvía, una voz queer. En relación con la película, a sus protagonistas, es esta noción de desvío la que queremos destacar. Esta doble capa de lo queer, por una parte el territorio propio de la infancia, y por otra, su estado de reclusión, de prisión, a causa de su desarrollo infantil desafiante a lo social, 
irreverente al imaginario adultocéntrico de una infancia pura e inocente a la que debemos llevar por el camino recto del bien (muy relevante para una película que se enfrenta a niños penalizados por transgredir los límites de la conducta considerada apropiada); esta es una infancia fuera de margen, más que marginal, una infancia incluso criminal. Su estado de reclusión en una institución estatal tiene como origen alguna acción de parte de los chicos que ha infringido las normas del buen actuar sancionado por el orden social. Su comportamiento "desviado" es precisamente uno que desafía o violenta la maduración en un sentido vertical, la que supone la adecuación a los marcos sociales establecidos. Los jóvenes que el documental nos permite observar de cerca son queer de un modo radical según los códigos conductuales que se les asignan. Lo que nos interesa reconocer en la película son las estrategias que reivindican otro tipo de desvíos y permiten hacer aparecer una imagen de ellos que escapa de los estereotipos y abre nuestra mirada. Así, los sueños operan como ese primer camino desviado, que al volverse foco de atención deja aparecer modos de representar que tuercen la convención. Permitirles soñar y que sus sueños sean importantes es ya un gesto reivindicativo que desarma el paradigma adultocéntrico y estigmatizante. En 24/7. Late Capitalism and the Ends of Sleep, hermoso ensayo dedicado a abordar el sueño como uno de los escasos reductos de la resistencia humana a un sistema obsesionado con la productividad y el consumo constante y sostenido, Jonathan Crary expone que un mundo insomne es uno desencantado que ha erradicado de sus territorios las sombras, la oscuridad y las temporalidades alternativas (Crary 2014, 18). Si bien el texto no se dedica exclusivamente a la actividad onírica, sino al acto y tiempo del dormir en general, es interesante destacar que en ese intento el autor enfatiza las cualidades subversivas de ese tiempo no productivo anclado en una atmósfera nocturna que promueve la aparición de lo espectral: "The spectral is, in some ways, the intrusion or disruption of the present by something out of time and by the ghosts of what has not been deleted by modernity, of victims who will not be forgotten, of unfulfilled emancipation" (Crary 2014, 20). Enfocarse en los sueños de estos niños, darles lugar a su palabra como continente de esas experiencias nocturnas, es también una puerta abierta a ese mundo negado por la vigilia productiva, es un desvío que reivindica sus voces como propias y que desata la potencia de lo oscuro.

En otras palabras, recogemos la noción de infancia queer en el sentido amplio que le da Bond Stockton, remarcando nosotras la idea de desvío, pero para reconocer primero la apreciación negativa que el campo social hace de ella en este caso particular, para luego buscar en la misma las estrategias que aparecen para confrontar la norma restrictiva. Así, nos aproximamos a los sueños que retrata el documental como manifestación de una experiencia válida que suspende a la vez que evidencia la privación de libertad y que, a partir del contexto particular de la historia y sus protagonistas, el director decide abordar desde el género del terror. Asimismo, nos proponemos recoger la relevancia de la sonoridad del relato oral, inserto en el paisaje sonoro del filme, como un modo de enfocarnos también en el desvío desde la tradicional hegemonía visual hacia los territorios rebeldes de la dimensión sonora de la imagen audiovisual, proponiendo que, junto con la idea de lo queer, le corresponde también un modo particular de describir la infancia: el sonido como manifestación primaria de la fuerza infantil.

Nuestra aproximación a lo queer a partir del film de Ballesteros se despliega desde la oposición ejercida por el aparato de control ante la desviación de los niños detenidos, pero que el documental vulnera por medio de su énfasis en los relatos oníricos como una dimensión contestataria ante el dominio objetivo de lo real y en el 
presente texto se subraya desde la estética asociada al género de terror y la importancia del paisaje sonoro construido en la película.

\section{Un gótico sureño}

La placa de madera ubicada en la entrada del edificio institucional y que sirve como marca identificatoria del mismo, tiene en efecto la imagen de un castillo tallado en relieve. Esta figura sirve como elemento fantástico que nos invita a reconocer en el relato documental algunos elementos ficcionales que provienen de una tradición literaria y fílmica asociada al terror. Particularmente nos detendremos primero en el género gótico, cuyo origen puede rastrearse en la Europa del siglo XVIII. Su tradición suele recurrir a ciertas locaciones como castillos, cementerios o calabozos abandonados, cuyo estado de desatención y ruina los convierte en espacios ideales para la aparición de presencias fantasmales. Una de sus características, según describe Gabriel Eljaiek Rodríguez en Selva de fantasmas: el gótico en la literatura y el cine latinoamericanos es la de desarrollar protagonistas que encarnan una profunda dualidad: "el protagonista es a la vez el antagonista", señala para enfatizar la ambigüedad radical de estos personajes, donde la lucha parece darse también en el interior. Algo de eso podemos reconocer en el documental y su valoración del paisaje onírico. Las pesadillas aparecen como fantasmas internos que se manifiestan y comparten en los relatos: gracias al montaje, las voces literalmente recorren las salas vacías del lugar durante la noche acechando a sus espectadores, y al mismo tiempo replican el miedo del que provienen. Esta estrategia de representación será uno de los elementos relevantes para nuestro estudio, donde por una parte destaca la importancia dada a la dimensión sonora del registro audiovisual y su utilización de modo no sincrónico, desmontando así la continuidad sonido-imagen en pos de la atmósfera inquietante, y por otra, se refuerza la renuncia a las oposiciones bien/mal, correcto/incorrecto, para mostrar las dualidades que habitan la infancia, en este caso relatadas desde el género del terror.

Luego de la primera escena de intercambio de experiencias oníricas entre dos reclusos (uno de origen mapuche y el otro gitano) que se basa en la conversación uno a uno en el espacio íntimo de la celda, se presenta este modelo de escenificación de los relatos que consideramos crucial para subrayar las estrategias de una estética del terror y también la relevancia de la dimensión sonora, sobre la que nos extenderemos más adelante. En estas secuencias el sueño es narrado por una voz que se vuelve incorpórea y que se acompaña de una música ominosa que será un sello dentro de la película. La edición compone en paralelo una serie de imágenes que recorren los espacios vacíos del edificio, como si la voz se trocara en un cuerpo invisible, que como un fantasma transita secretamente por estos lugares a esa hora deshabitados. Los reclusos se encuentran encerrados en sus respectivos espacios de descanso, mientras los sueños parecen rebelarse al encierro para deambular por la noche del lugar y revelar que ese descanso es sólo aparente. 


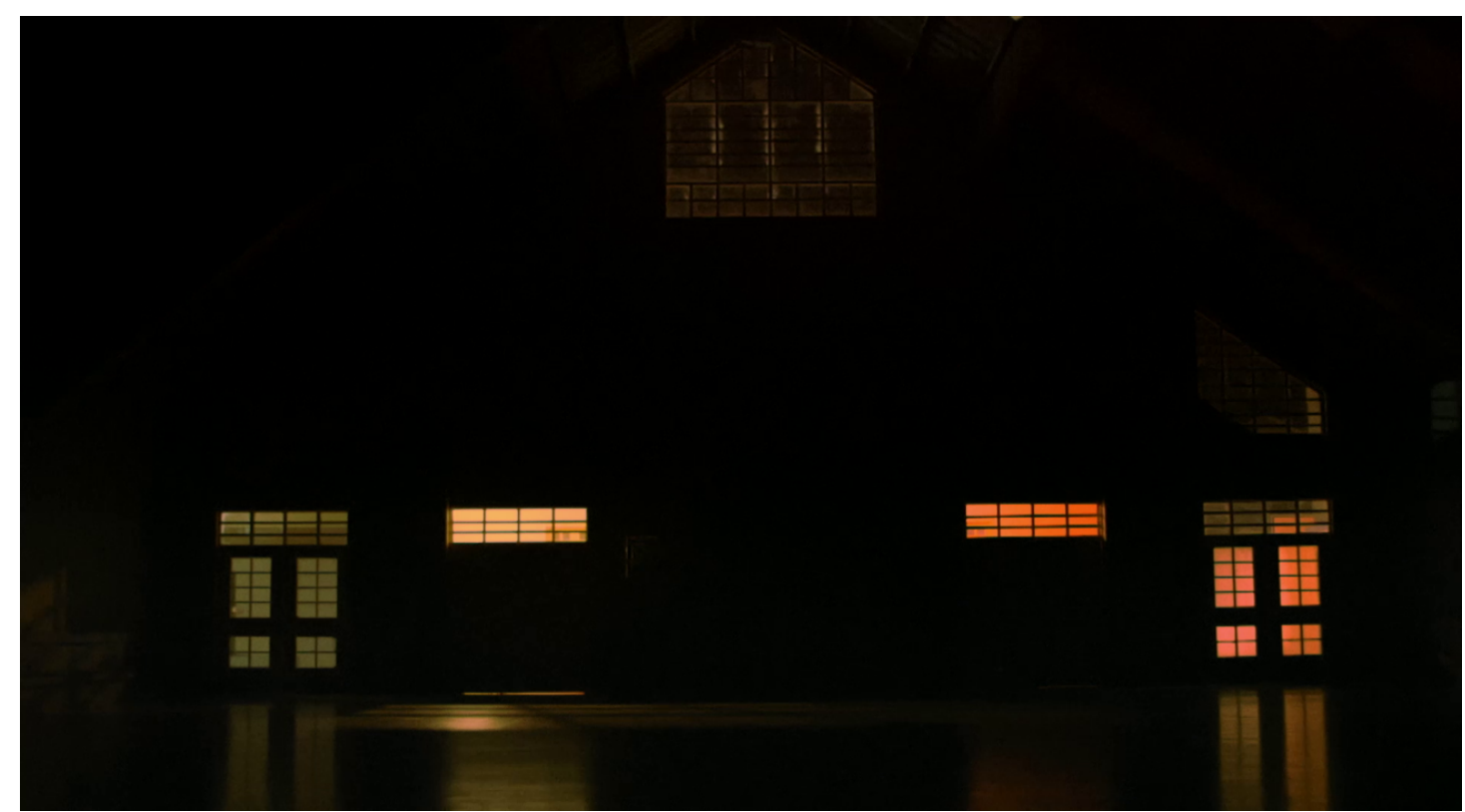

Figura 1. Los sueños del castillo, René Ballesteros, 2018

Además de esta consideración sobre posibles vinculaciones formales con el gótico, nos interesa recoger la traslación que Eljaiek realiza para situar y estudiar el gótico en una particular geografía latinoamericana:

Poner fuera de lugar personajes y temas propios del gótico europeo y norteamericano, situándolos en entornos latinoamericanos para transformar, homenajear y criticar el género -tropicalizar lo gótico-, es lo que se ha venido haciendo desde mediados del siglo XIX en la literatura latinoamericana -y, posteriormente, en el cine- recurriendo de manera extensa al horror, el terror y la ambigüedad.

(Eljaiek 2017, Introducción, localización 711)

En este caso, nos preguntamos si es posible plantear que este gótico tropical toma ahora otros desvíos para ubicarse en el campo sureño chileno, en medio de un clima frío y húmedo, en un paisaje brumoso, dialogando además con la historia del cementerio ancestral ubicado bajo la edificación. El protagonismo del paisaje se deja sugerir desde las primeras escenas; de hecho, la secuencia inicial, que es inmediatamente anterior a la identificación del edificio a través de la placa ya mencionada (sobre la imagen del castillo se lee: "Gendarmería de Chile, "Labor Omnia Vincit / el trabajo abnegado todo lo consigue"), se despliega en plano medio el cuadro de unas vacas pastando en el sector aledaño a la edificación. La atmósfera que se crea está fuertemente marcada por la banda sonora, cuya presencia dentro del film es recurrente y estratégica. En este caso, destaca la tensión entre la postal visual que de otro modo podría leerse desde el cliché del espacio natural como descanso y sosiego, y la música inquietante que desarma el estereotipo del espacio natural puro y predecible, para generar incomodidad en la audiencia. Leemos este gesto como un intento por desnaturalizar la naturaleza y leerla desde la dimensión problemática de la cultura. En este sentido, no es menor que el espacio geográfico esté situado en la Región de la Araucanía, y que junto a las connotaciones vinculadas a una tradición ancestral (y en la que la relevancia de los sueños es un elemento importante para este análisis) se asocia también a la politicidad de un territorio y las violencias sistemáticas sobre su gente. Es posible tal vez asociar 
esta recurrencia del paisaje desde un descentramiento de sus atributos con lo que plantea Jens Andermann respecto de las figuraciones del paisaje en el cine latinoamericano reciente:

\begin{abstract}
Me gustaría pensar los modos de aparecer de lo ambiental en ciertas zonas del cine contemporáneo de Latinoamérica como un desplazamiento del primer al segundo sentido del paisaje que acabo de bosquejar: del paisaje como presencia de un Real que insiste e irrumpe en la continuidad diegética al paisaje que desvanece cualquier presencia, al mismo tiempo que abre nuestra mirada a la emergencia de una vida precaria en el borde incierto entre lo inhumano y lo inmundo.
\end{abstract}

(Anderman 2018, 372)

De esta manera, las imágenes del entorno natural en que se emplaza el edificio institucional son una entrada de una temporalidad que suspende la narración y se inscribe en una atmósfera aterradora gracias a la banda sonora, así como también se materializa en un espacio de inquietud y borde, donde el ordenamiento del mundo desde una lógica antropocéntrica y profundamente adulta se dispersa y muta, como los restos humanos del potencial cementerio se funden con la materia de lo viviente en un sentido amplio. En estas escenas el paisaje es de alguna manera también una aparición espectral.

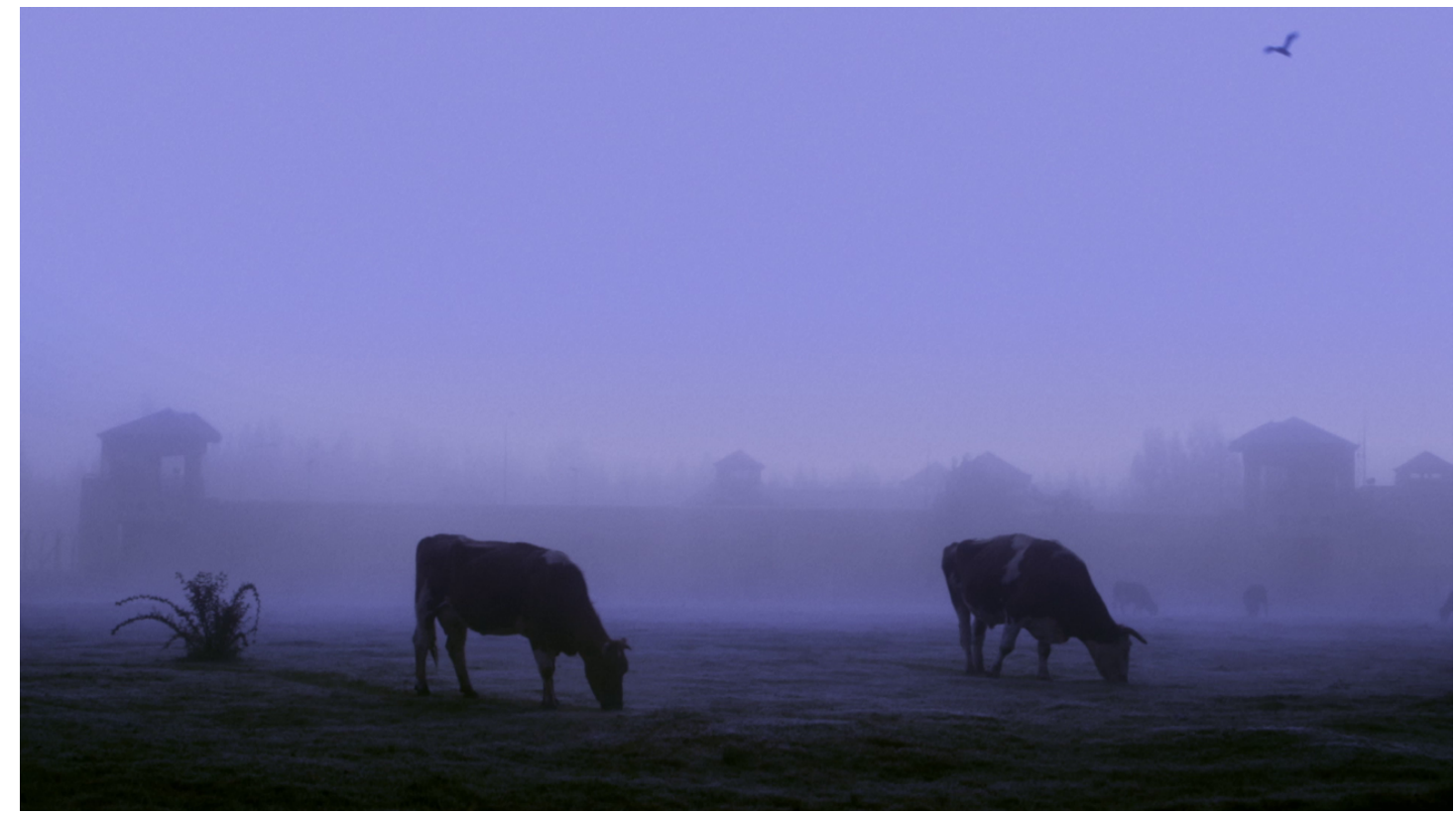

Figura 2. Los sueños del castillo, René Ballesteros, 2018

Seguido esta escena de "entorno natural" donde las vacas pastan, vemos a los niños reclusos sentados, algunos abrazados, frente a la televisión. ¿Qué ven? Un noticiero chileno, donde si prestamos atención, la noticia gira en torno a vacas, vacas que no están donde debieran estar, vacas insurrectas que por infringir la ley de la naturaleza -ser lo que se es- serán llevadas detenidas. Todo lo descrito causa mucha gracia a los niños: "las vacas se van en cana -presas", como ellos. El horror ha devenido en risa, pero una que se emplaza como mecanismo de defensa frente a la realidad del control.

Desde otro punto de vista, abordamos el relato de terror a partir de lo que Henri Michaux propone, en Una vía para la insubordinación, acerca del fenómeno 
sobrenatural del poltergeist. Michaux lo describe como la manifestación de una fuerza rebelde que no proviene de un agente externo sino de las energías insurrectas de un niño o niña que habita la casa. Recordemos que este fenómeno está relacionado con una presencia que se deja sentir a través de acciones que trastocan el orden de la casa familiar y generan desconcierto entre sus habitantes. Suelen ser acciones menores como mover muebles, trasladar objetos o hacerlos sonar (en alemán el significado literal de la palabra es "fantasma que hace ruido" y este énfasis dialoga muy bien con uno de los apartados siguientes de este texto), lo que generalmente lo ha caracterizado como una especie de espíritu juguetón o travieso. En una de las escenas del documental vemos a tres cuidadores del centro de reclusión conversando sobre su trabajo en el lugar, hasta que uno de ellos desliza la anécdota sobre algunas experiencias paranormales en las casas que conforman el complejo. Se da a entender entonces que el edificio puede estar poseído por alguna presencia sobrenatural. La conversación sugiere que esta penadura podría estar relacionada con el cementerio que se asienta bajo sus pies. Es verdad que antes de este relato y de la mención inicial a la ubicación del sitio sagrado, la atmósfera de agobio y temor está sobre todo dada por la impronta de las narraciones de los sueños de los jóvenes. Se hace más interesante entonces poder dar un lugar a lo planteado por Michaux, y construir un paralelo entre la materialización del miedo por parte de un agente externo (los espíritus que habitan el cementerio), y de uno interno (la energía sublevada de los mismos reclusos). La escena es interrumpida justamente por un ruido, es el sonido del estómago de uno de los cuidadores: al igual que el episodio de las vacas prisioneras, el humor se cuela, pero de un modo ominoso cuestionando aún más los márgenes de lo real.

En su texto, Michaux destaca la opresión de la casa familiar con sus reglas y normativas al compararla incluso con una cárcel:

El niño está hecho para la libertad de movimientos. La casa, sede de tantas prohibiciones, impresiona a la criatura desde su edad más tierna. En esta prisión "moran" y se demoran muebles y objetos pesados, un conjunto mucho más detestable (si es detestado), más odiado, y odiado en vano, de un modo más inolvidable que los padres, más habitado por lo oculto, más petrificado, más insistente (y a una edad temprana, más gigantesco). Ahí es donde se desarrolla el ritual de la cotidianidad que parece que nunca vaya a tener fin.

(Michaux 2015, 34)

Ante ese orden "petrificado" de obligaciones y reglas es que se rebela de manera inconsciente la fuerza infantil y se deja aparecer en acciones que parecen provenir de un origen desconocido y aterrador. Para Michaux el origen es claro y se corporiza en ciertos "atentados" que el niño o niña perpetra sin saberlo, sólo para perturbar el orden burgués y sus prohibiciones. Esa energía insurrecta "aborrece un interior" (Michaux 2015, 34).

Imposible no hacer referencia aquí a la narrativa biográfica de muchos niños y niñas que son custodiados por el SENAME. ${ }^{5}$ No es raro que a su internación en estos hogares de supuesto cuidado en el que los maltratos y desatención les hacen querer escapar de su tutela a cualquier costo, les siga la reclusión en casas similares a la que muestra el documental y más tarde, cuando ya son adultxs, les lleve a habitar las ya

\footnotetext{
5 SENAME es la sigla para Servicio Nacional de Menores, institución estatal que debe velar por resguardar los derechos de niños, niñas y adolescentes. En los últimos años su funcionamiento ha sido altamente criticado en el debate público a causa de las visibilización de los abusos y malas prácticas sostenidas que sufren quienes están bajo su cuidado.
} 
sobrepobladas cárceles chilenas. Al abordar la delincuencia juvenil en el contexto neoliberal chileno, del que esta trayectoria de encierros forma parte, Alejandro Tsukame Sáez la define como un "campo discursivo e institucional conformado por especialistas, ideologías, tecnologías y programas para el control del comportamiento 'antisocial' de los menores de edad, que suponen saberes específicos sobre las causas y los remedios que se consideran más adecuados" (Tsukame 2017, 8). Esta "compleja construcción social" se ve interrogada en su estudio a fin de develar este "campo institucional de poderes y saberes responsables de la configuración social de un sujeto precarizado y vulnerado, de un extraño" (Tsukame 2017, 12). La cimentación de esa otredad constituye una perspectiva donde parece no haber para ellxs un exterior al cual salir y desprenderse de la opresión de "la casa", cuando la casa no es el hogar sino el castillo aterrador. La pesadilla no habita sólo los sueños, sino que se inviste en la realidad y ahoga cualquier tipo de sueño en el sentido de una posibilidad de imaginar un futuro distinto. Una de las frases emblemáticas del movimiento estudiantil chileno que se manifestó masivamente en 2011 rezaba: "si no nos dejan soñar, no los dejaremos dormir": el poltergeist como la materialización de una rebelión frente a un mundo convertido en prisión.

\section{Sueños}

Los aportes de la teoría psicoanalítica fueron cruciales para dar relevancia a la vida onírica dentro de los márgenes de validación en la cultura occidental. La interpretación de los sueños de Sigmund Freud, publicada por primera vez a finales del siglo XIX, significó para su autor el poder exponer de modo más metódico sus teorías acerca del funcionamiento del aparato psíquico y la relevancia del inconsciente dentro de sus operaciones. Movimientos artísticos de vanguardia como el surrealismo o el dadaísmo recogieron este interés por explorar el territorio inconsciente, con los sueños como ejercicio privilegiado, cuestionando así la supremacía de la racionalidad consciente en nuestros procesos de individuación y de relación con el mundo. Podemos afirmar entonces que estas aproximaciones a las fuerzas inconscientes en general y los sueños como una experiencia legítima del mundo, le han otorgado mayor valoración dentro de los márgenes del pensamiento occidental. Sin embargo, podemos señalar también de qué manera, además de definirlos a partir de una diferenciación tajante respecto de la vida consciente, han quedado circunscritos a estos dos ámbitos como espacios predilectos de su desenvolvimiento: el de la práctica clínica psicoanalítica y el de la expresión artística,

La figuración de los sueños en el documental no se sitúa en ninguno de estos espacios. Las conversaciones se dan en las habitaciones de los jóvenes reclusos, en un ambiente que por una parte evoca cierta intimidad entre ellos, pero que a la vez -por su situación de encierro forzado, las razones que los llevaron ahí y el contenido de la generalidad de los sueños que narran- se encuentra asediada por una atmósfera de tensión y desasosiego. En una conversación organizada por MIRADOC 6 para promover la presentación de la película en salas (virtuales), Ballesteros explicitó su propia relación con los sueños al relatar que en su tradición familiar estaba muy instalado el contarse los sueños y darles importancia, pero sobre todo este hábito de compartirlos. Esta era una costumbre que había adquirido de la convivencia con su abuela durante la

6 Panel "Infancia, encierro y salud", organizado por MIRADOC. 23 de marzo de 2021. https://www.youtube.com/watch?v=fLYHunSN9fY. 
infancia. Contó también que, al llegar a Francia, a sus conocidxs les parecía raro que él contara los sueños, no por no ser importantes, sino porque con quien se comparten es con el analista. Es interesante este contrapunto en que los sueños por una parte se comparten, se narran y en la otra sólo se narran en determinado espacio. Esta declaración refuerza de algún modo lo señalado anteriormente, en cuanto este posicionamiento de los sueños dado por la escuela psicoanalítica es también una valoración sitiada, que sólo se autoriza en determinado contexto. Cuando el director enfatiza este aspecto, lo hace también para señalar el carácter mestizo de su propio relato, anclado en su experiencia biográfica en la ciudad de Temuco. Sin entrar en más detalles respecto del tema, deja entrever los alcances de la cultura mapuche en relación con la manera cómo se entienden e integran los sueños a la vida cotidiana.

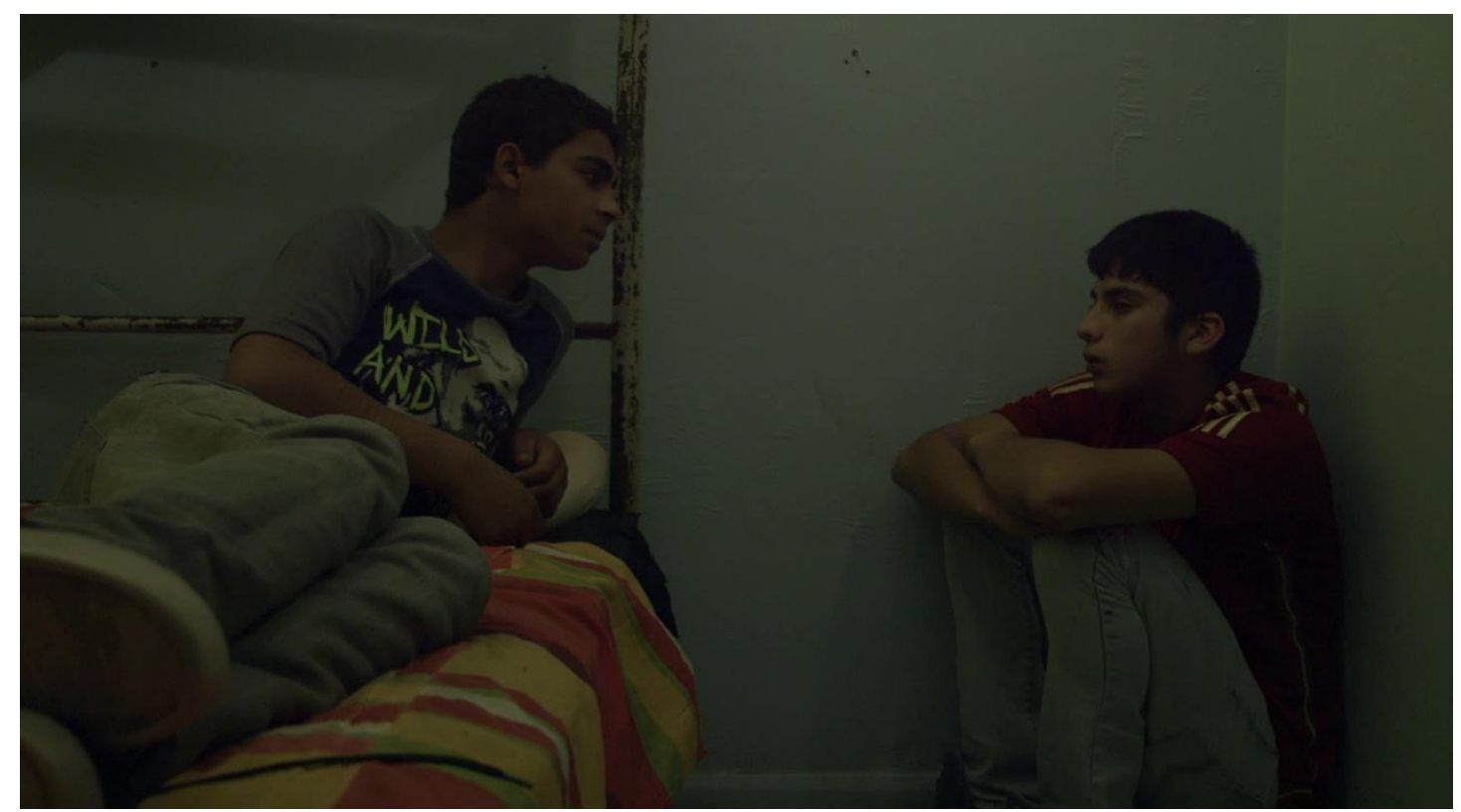

Figura 3. Los sueños del castillo, René Ballesteros, 2018

Para Armando Marileo Lefío, mapuche que se ha encargado de transmitir la cosmovisión mapuche, el asunto de los sueños -y cualquier otra categoría a revisardebe entenderse en el plano de la circularidad de esta cosmovisión, no se puede pensar la vida separando la vigilia del sueño, la salud de la educación, el trabajo del cuerpo etc. ${ }^{7}$ Tal vez esto nos permite entender mejor la escena antes referida en que un joven mapuche dialoga con un joven gitano, es el primero el que insiste reiteradas veces en la categorización de los sueños como pertenecientes a una u otra cultura: ¿cómo son los sueños gitanos? ¿cómo sueña un gitano?, quiere saber. La cosmovisión mapuche comparte con otras culturas ancestrales la importancia dada a los sueños como señales o mensajes a interpretar. Así, la oniromancia o interpretación de los sueños es parte de las prácticas valoradas en la comunidad, y suele estar asignada a una de las prerrogativas de la machi. Uno de los pocos momentos dentro del documental en que la tensión se disipa es la conversación, en un espacio abierto natural, con la machi joven que es pareja de uno de los reclusos. En esta escena la naturaleza aparece en un código muy distinto al que hemos señalado anteriormente, más ligada al reposo y la calma. La

\footnotetext{
${ }^{7}$ Txawün participativo constituyente "Cultura y principios mapuche" relizado el 16 de febrero de 2021 a través de Facebook Live.
} 
joven también relata sus sueños y cuenta además acerca de la conexión que existe entre ella y su pareja, de manera que sus estados internos se transmiten pese a la distancia.

¿Qué pasa con los sueños de quienes habitan los territorios de la hegemonía cultural? En el caso de la infancia se ha podido observar que mientras menos escolarización tienen lxs niñxs, menor es su grado de razonamiento -entendido como ratio/cuantificación de lo medible- y mayor es su grado de pensamiento -construcción imaginaria que cuestiona el orden oficial-. Cuando lxs niñxs de la "primera infancia" -así le llaman las teorías del desarrollo, pero acá estamos entendiendo a la infancia más allá del cronos por tanto no caben las secuencias- despierta, generalmente narra lo que ha soñado de manera espontánea, compartiendo aquello que recién ha sucedido. Para lxs niñxs no hay una separación tajante entre realidad y sueño, por cuanto no hay necesidad de una verdad absoluta. Vemos aquí una conexión entre la cosmovisión mapuche que nos presenta Armando Marileo y la vida infantil, que no ha ingresado completamente a los rígidos parámetros de su cultura: no está, aparentemente, la imperiosa necesidad de clasificarlo todo, de dividirlo todo, de crear dualidades y separaciones.

Los sueños del castillo, encarna una interrogante respecto de los límites de la realidad y de lo real, respecto del ser marginado y marginal. Los sueños del castillo institucional retratado aquí no son gratos sueños de anhelos infantiles o infantilizados, son pesadillas que angustian, que miran de frente, que exigen, que dan órdenes. Por la manera cómo la película aborda los relatos oníricos, así como por el mismo contenido de los sueños que varias veces relatan situaciones de violencia similares a las que los niños han protagonizado en sus vidas anteriores a la reclusión, muchas veces la frontera entre el espacio del sueño y el de la vigilia se disipan. Así, el relato permite ver su contigüidad y perder esos límites. Esta incertidumbre contiene también un rasgo aterrador, no saber dónde se está y perder la capacidad de incidir en lo que ocurre alrededor. Una de las escenas que refuerza esta sensación de inquietud es la del relato del sueño en una secuencia de narración onírica con sonido sincrónico (vemos a quien lo cuenta) en que el joven describe sucesos similares a los del poltergeist (objetos que se mueven o cambian de lugar) y además recuerda un sueño del que no podía escapar: "soñaba que despertaba y todavía estaba dormido". De alguna manera, este sueño evoca también la experiencia de opresión destacada por Michaux y que como vimos con Tzukame Sáez, obedece también a un constructo institucional ideológico que limita sus posibilidades de ser. El recurso aquí utilizado diverge del que describimos anteriormente, sin embargo, en este caso la continuidad entre sonido e imagen se disloca porque lo que se narra no está realmente en escena, sino que describe los hechos ominosos, y de esta manera, al igual que en las escenas de sonido asincrónico, produce el efecto fantasmal de lo que no puede verse, y en ambos casos alimenta la imaginación aterradora desde la potencia de la voz, en un caso atada al cuerpo y en el otro desapegada de él.

\section{La voz del fantasma}

Nos interesa explorar ahora la dimensión sonora como un desvío o reacción a la dominancia de la visualidad en la imagen cinematográfica y también en la cultura occidental. Ya vimos que la traducción de poltergeist es literalmente "fantasma que hace ruido". Esta definición se encuentra muy en línea con el énfasis que queremos dar a la aparición del sonido como desestabilizador de los órdenes establecidos. El equipo 
de realización trabajó teniendo esto último en consideración a la hora de tomar ciertas decisiones de montaje y al privilegiar la relevancia del diseño sonoro y la música original (a cargo de Simón Apostolou y Alexandre del Torchio, respectivamente) dentro de la puesta en escena. En una entrevista realizada al director durante la escritura de este texto, Ballesteros comenta que el trabajo de edición se llevó a cabo muchas veces privilegiando el avance en el diseño sonoro: "La música y las capas de diseño sonoro se fueron insertando a medida que el montaje avanzaba. En ocasiones, muy a menudo en realidad, la composición, la materia sonora nos ayudaba a escoger los planos, partiendo del sonido" (conversación con el director vía correo electrónico, 10 de mayo de 2021).

En su estudio sobre la voz, Mladen Dolar enfatiza la importancia de la voz dentro de la teoría psicoanalítica a partir de Lacan. Uno de los aspectos que nos gustaría destacar es la idea de la voz como cuerpo ajeno, en la que su carácter físico es una perturbación incluso para el lenguaje mismo, ya que su ajenidad corporeizada es la que lo elude a la vez que lo contiene (Dolar 2006, 131). Nos interesa esta aproximación a fin de volver sobre uno de los recursos ya descritos en que se presentan las imágenes del recinto en medio de la noche, con las voces recorriéndolos como presencias inmateriales. Tal vez una de las cuestiones aterradoras de la voz en este contexto sea justamente esta corporeidad inmaterial. La voz es materia, pero casi pareciera no serlo, como los fantasmas. Por otra parte, y también esto lo destaca Dolar, el análisis de los sueños privilegia la dimensión visual de los mismos (Dolar 206, 136); nos parece relevante entonces que una obra que se centra en los sueños los capture como relatos orales, habitantes de esas voces espectrales.

"Todo aquello que es perceptible puede ser percibido en su aparecer" (Seel 2007, 123). La problemática puede estar, entonces, en el lugar y jerarquías que como cultura occidental hemos dado a los sentidos. El razonamiento occidental moderno nos enseña que los sentidos nos engañan, el sueño nos engaña, sólo el razonamiento nos hará con la verdad. Así, la vista, sentido no proximal por excelencia, construye su confianza en esa misma distancia y en su capacidad para dominar lo que le rodea. En Ver y hacer ver, Nelly Schnait expone la predominancia de la visión en la cultura occidental, relacionándola no sólo con el placer asociado a ella sino sobre todo con sus propiedades para establecer un saber respecto del mundo. Señala la autora que para Hegel se trata del sentido "más intelectual", por hallarse "exento de deseos" (Schnait 211,18 ). De alguna manera, este énfasis separa a este sentido perceptivo de las tribulaciones del cuerpo y le da un carácter más mental. ¿Pero, qué pasa con lo determinado, con lo dado, con lo normado, con lo recto, una vez que se cierran los ojos? ¿Una vez que quien cierra los ojos es un niño, un niño prisionero? “(...) es admirable que el supremo ideal del ser vidente sea el "ojo de águila". El águila acecha su presa, cae sobre ella y la atrapa. Este es un ideal propio del hombre occidental, un hombre acostumbrado a contemplar el mundo entero como su presa (...)" (Berendt 1986, 13). ¿Pero si en lugar de "ver la presa" se escuchan las voces? ¿si en lugar de entrar por los ojos, las imágenes entran por los oídos? Así parece ser lo que enfrentan los protagonistas de este documental, no se trata sólo de lo que ven en sus sueños, una vez que cierran los ojos, se trata de lo que oyen, de las voces y de lo que dicen también esas voces. "Nuestra conciencia del yo se halle en estrecha relación con las percepciones sensorias (...) cerramos nuestros órganos sensorios cuando perdemos nuestra conciencia diurna, es decir cuando queremos dormir" (Aeppli, 2017, 4). ¿Cuál es la puerta que se abre entonces al soñar? ¿qué fantasma entra y para qué emite esos ruidos en nuestra conciencia? 
El paisaje sonoro del film cumple un rol fundamental en la construcción atmosférica de la película, hay un especial acento que refuerza el discurso estético particular y universal del territorio en el que se manifiestan los sucesos narrados. Es el sur de Chile, es territorio rural, todavía puede oírse el frío de una mañana con neblina. Tal vez el habitar ese tipo de tiempo y espacio, posible en la ruralidad marginal ante los límites normados de la ciudad, es lo que potencia que Gabriela Mistral, mucho antes que Berendt pusiera la atención en la escucha y cuestionara la supremacía de la vista incluso en el lema patrio del escudo nacional de Chile. A Gabriela Mistral seguramente le influyó vivir en territorio rural, pisar, oler, sentir, tocar y escuchar la otredad. Al parecer, como algo se deja ver en la película, los mayores momentos de vacío, los ritmos y ciclos vitales más comandados por la naturaleza, permiten a las personas desarrollar una escucha más determinante que lo que simplemente alcanzamos a ver. Menos Cóndor y más Huemul pedía la pensadora ya en los principios del siglo pasado: “(...) El maestro de escuela explica a sus niños: 'El cóndor significa el dominio de una raza fuerte; enseña el orgullo justo del fuerte (...) hay tanta águila, tanto milano en divisas de guerra, que ya dice poco, a fuerza de repetición, el pico ganchudo y la garra metálica. Me quedo con ese ciervo, que, para ser más original, ni siquiera tiene la arboladura córnea (...) Lo defiende la finura de sus sentidos: el oído delicado, el ojo de agua atenta, el olfato agudo. Él, como los ciervos, se salva a menudo sin combate, con la inteligencia, que se le vuelve un poder inefable" (Mistral 1926, 5).

Otro punto que nos parece relevante en la película es el lugar de la escucha en la propuesta fílmica de Ballesteros ¿Qué es lo que realmente nos están diciendo las palabras de este par de niños torcidos? "André Bazin escribe: 'El niño no puede ser conocido más que desde el exterior. Es el más misterioso, el más apasionante y el más turbador de los fenómenos naturales. ¿Cómo el novelista, que utiliza las palabras de la tribu de los adultos, o el pintor condenado a fijar en una síntesis imposible ese puro comportamiento, esa duración cambiante, podrían pretender lo que la cámara nos revela: el rostro enigmático de la infancia? Ese rostro que os enfrenta, que os mira y que os escapa'. El cine nos pone cara a cara con la infancia, dice Bazin" (Larrosa 2007, 19). La palabra, el significado, el significante de esta lengua extranjera, también es gesto y como gesto es enigma. No se trata entonces de escuchar y comprender un mensaje, al parecer la propuesta del director es llevarnos al gesto perturbador terror/enigma- de no poder codificar al otro -infancia/queer- No saber con exactitud el margen de lo que se escucha, el margen real o más bien cómo ordenar este margen, es el paisaje sonoro político que nos presenta este documental.

En Teatro posdramático Lehmann dedica un interesante análisis al landscape play de Stein, a nuestro parecer, un profundo cuestionamiento a los modos paradigmáticos con los que occidente concibe la percepción -en todos los ámbitos- $\mathrm{y}$ cómo esto ha repercutido, necesariamente en el arte y, sobre todo, en el "sustento" del quehacer del artista. El landscape play es un llamado de atención sobre el fenómeno de la temporalidad en la percepción y de ahí, una crítica a la necesidad de sentido o bien de producción de sentido en la que se enfrasca el creador/a. "Stein aboga por poder observar aquello que ocurre en la escena tal y como se contempla un parque o un paisaje" (Lehmann 2013, 110).

Si retomamos esta idea de la infancia como ausencia/desvío/quiebre de voz otredad queer- podemos relacionarlo con el teatro posdramático de Wilson donde "el fenómeno tiene prioridad sobre la narración (...) la contemplación se encuentra por encima de la interpretación, con lo que se crea un teatro del tiempo de la mirada" (Lehmann 2013, 140-141), -la mirada de la escucha diremos acá. 
Volvamos a esta idea de un ojo vigilante que acecha. Uno de los protagonistas narra su sueño, lo narra con urgencia y sin separación de realidades o verdades consensuadas. Él está efectivamente encerrado en un castillo, que tiene torre, que tiene un fuerte, que tiene límites, y a su vez sueña que está en un castillo, un castillo con dos guardianes "un águila de día y un murciélago de noche", según sus propias palabras. De día la vista hegemónica, aguzada, de noche un murciélago, animal de escasa visión, a la vez que considerado uno de los mamíferos que mejor sobreviven a entornos difíciles -como esta infancia queer-. El murciélago utiliza ecolocalización para guiarse, que podría describirse como un potente sentido sonoro como ruta de orientación. De día la vista, de noche el oído. ¿Cómo separar entonces los límites de realidad entre sueño y vigilia? ¿El sueño es sólo una reproducción de la conciencia o algo que la razón nos ha impedido conocer? El documental permite que se produzca esta "otra voz" que habla desde el gesto, desde la pregunta, desde su inocencia y perversión. "Conviene recordar que un acontecimiento supone la sorpresa, la exposición, lo inanticipable" (Derrida 2006, 81). La infancia es lenguaje de gesto, la palabra es gesto y como gesto es acontecimiento. Asistimos en esta experiencia fílmica a la representación sonora que se arrima como un constante inanticipable de quien escucha.

La última escena de la película es bastante perturbadora. El sello ominoso de la música se expresa cabalmente en esta secuencia, mientras las imágenes cuya textura es la de las cámaras de vigilancia que ya antes han formado parte de los registros incluidos en el documental, exhiben figuras escasamente reconocibles. El uso del zoom en una tecnología que no se caracteriza por su extrema fidelidad desfigura lo que captura, de manera que en la escena se potencia una sensación de irrealidad inquietante que es la que acompaña a las pesadillas. Este recurso, que implicó usar el mando de la cámara de vigilancia con un joystick y luego grabar directamente desde el monitor (aumentando así más aún la dispersión de lo registrado), podría sintetizar en gran parte lo propuesto en este trabajo. Este sueño de la técnica usada para el control deviene en una imagen que retrata la imposibilidad de controlar la fuerza contestataria del desvío radical de esas vidas que se quiere vigilar y restringir.

La relación entre sueño y vigilancia es también estrecha. En el texto mencionado al inicio de este artículo, Jonathan Crary expone de qué manera poder dormir implica un acuerdo de confianza entre el durmiente y la comunidad a la que pertenece. Cuando dormimos estamos en un estado de vulnerabilidad que requiere sentirnos segurxs respecto de nuestra integridad mientras no podemos defendernos del entorno. Esta relación adquiere un rasgo peculiar a partir del siglo XVIII cuando dicha vigilancia pone en acuerdo la propiedad y el privilegio de entregarse al sueño (Crary 2014, 26). Quienes tienen bienes que resguardar requieren obtener de parte del estado esa tranquilidad para poder ejercer su necesidad vital devenida en privilegio. En el universo de la película la vigilancia opera en un sentido opuesto. No es el sueño de los niños residentes lo que se cuida, sino el que mientras aparentan dormir no traten de escapar. Son ellos la amenaza para la tranquilidad de la propiedad ajena y el orden. Es curioso que el mismo libro - cuyas referencias culturales son numerosas- mencione respecto de este asunto la novela El castillo de Franz Kafka, para ilustrar un escenario en el que la seguridad no está asegurada y lo que vive el personaje es más bien un inquietante insomnio en permanente alerta. Este castillo no es el de la tradición del gótico sino el de las vidas modernas en constante desasosiego. Que la película se centre en los sueños de los niños reclusos es por una parte una materialización de su derecho a dormir, y que luego a través de estos relatos perturbadores narrados como espectros que deambulan 
por el lugar, nos confronta con la precariedad de sus vidas transformadas en imágenes de sueños que no son descanso.

En la escena final referida, lo que vemos sin poder ver a través de la cámara de vigilancia, son esos sueños pesadillescos que hablan por ellos, rompiendo los límites de lo decible. La imagen recorre desde el espacio natural inmediatamente contiguo hasta los muros que rodean el edificio. Como si este sueño convulso fuera la única puerta de salida.

\section{A modo de cierre: la maleza en permanente desvío}

Nos parece que uno de los logros del filme de Ballesteros es ponernos en tensión con esa infancia queer, con esa otredad marginada pero que a su vez habita el margen o más bien lo traspasa. La película de Ballesteros desborda esos límites, y nos presenta el desafío de lo queer en la infancia, generando interrogantes que se sitúan siempre más allá del bien y del mal; más allá de los límites de la realidad y de lo real, más allá de ser niños marginados o marginales.

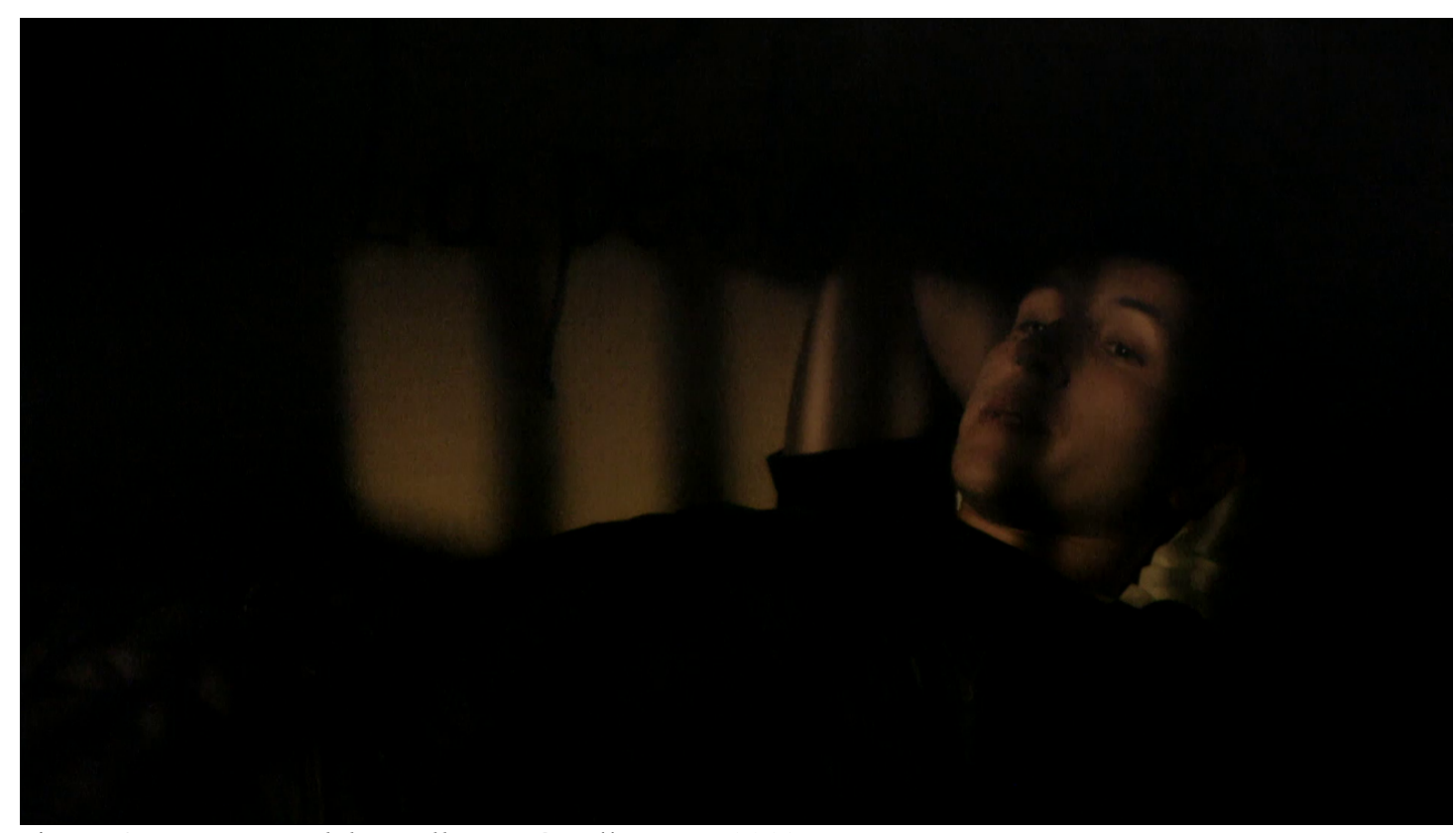

Figura 4. Los sueños del castillo, René Ballesteros, 2018

Ampliar la mirada de lo queer permite superar el encasillamiento o normativa que, al sobredefinirla y delimitarla, estaría al mismo tiempo declarando su fin. ¿Puede una insurrección mantener su pulso insurrecto si se sabe de dónde viene y hasta donde puede o les es permitido llegar? Entender a la infancia como lo plantea Kathryn Bond Stockton, desde su carácter desviado e impredecible, sumar a aquello las capas de la marginalidad, el delito, la alteridad cultural, vuelve aún más poderoso este abismo de lo queer, no sólo como una cuestión de género y sexualidad. Hemos querido abordar esta perspectiva a través de un documental que se hace cargo de la vida de un grupo de menores de edad catalogados como desviados por el aparato jurídico estatal, para reivindicar otros desvíos desde donde posicionar la mirada. Es así que la exploración del documental de género, a través de recursos que construyen una atmósfera aterradora que se ancla en las pesadillas desde el relato sincrónico y asincrónico de las mismas, 
funciona como un primer intento por retratar esas existencias fuera del estereotipo y permitirles soñar. Aun cuando esos sueños representen la violencia instalada en sus vidas psíquicas, pone atención en ellas y desde ahí las autoriza. La narrativa se construye desde la posición mestiza de un viaje onírico que no es sólo lectura del inconsciente de quien sueña, sino señales de otros mundos que habitan este. Por otra parte, el trabajo sonoro desafía la predominancia de la dimensión visual y genera nuevos caminos desde donde observar el universo de sus protagonistas. Nos parece que la escena final mencionada en el apartado anterior es crucial para entender el vuelco que la película ejerce sobre estos aparatos de control y estigmatización. El uso que se hace de la cámara de vigilancia, cuya finalidad es cautelar que los órdenes del espacio se mantengan a través de una mirada técnica constante y omnipresente, al transformarla en un aparato expresivo, que, desde nuestra lectura de las imágenes incomprensibles, retrata esos sueños oscuros que nos han narrado los niños que habitan el castillo, expone esta desviación desde la producción misma de un imaginario. Una escena en la que además el diseño sonoro es fundamental para crear la experiencia de ajenidad que sugieren las imágenes y que desplaza su objeto hacia el límite entre el muro que los constriñe y la naturaleza. Su desviación es concreta (mover el objetivo de la cámara) y además intensifica el acercamiento del ojo tecnológico hasta hacer irreconocible lo que registra, volviendo inútil el dispositivo de control.

Lo queer de la infancia, que nos parece está claramente manifestado en esta película, es la superación de dualidades opuestas para crear la narrativa de una realidad, el marcado desvío de la idea de un único camino que aparece frente a la negación de su opuesto. Pensando en esta construcción de límites que se impone, y cómo la infancia queer se rebela habitando el margen, nos parece importante destacar en la película el relato del lugar límite para los cuerpos, la "línea de fuego", arquitectura frágil que señala la demarcación que no se puede traspasar, a riesgo de perder la vida en ese intento. Paradójicamente en medio del cemento, la franja de pasto, único espacio donde reina una naturaleza algo más indómita, es el límite entre la vida y la muerte para los niños que habitan el castillo y sus sueños. Pasar la franja de fuego es riesgo de vida, ahí donde crece la maleza, atrapada en la franja caprichosa del vigilante de la torre panóptica, límite de muerte, siendo que ella, la reina queer de la naturaleza, está destinada a ser siempre vida -hierba mala nunca muere- a crecer donde no debe, a ser extirpada por inútil y fea, $\mathrm{y}$, así y todo, volver a crecer siempre torcida, desafiando los márgenes, una y mil veces, cómo los niños presos vuelven a aparecer, la misma sangre en distintos cuerpos. La torre del castillo no sólo vigila los sueños de los niños, también los límites de la maleza irreverente. Fuera del castillo reina la naturaleza, la vida, dentro del castillo la naturaleza es el límite de la muerte para la propia vida que porfía.

\section{Bibliografía citada}

Aeppli Willi. 2017 [1996]. "Introducción: El organismo sensorial, su atrofia y su cultivo”. En Cuadernos Pau de Damasc, 4-5. Tercera Edición. Limache, Chile.

Anderman, Jens. 2018. Tierras en trance. Arte y naturaleza después del paisaje. Santiago: Metales Pesados. 
Ballesteros, René, dir. 2018. Los sueños del castillo. Temuco: La Ballesta Films.

Berendt, Joaquim-Ernst. 1986. Nada Brahma. Dios es sonido. Buenos Aires: Editorial Abril.

Bond Stockton, Kathryn. 2009. The Queer Child or Growing Sideways in the Twentieth Century. Durham y Londres: Duke University Press.

Crary, Jonathan. 2014. 24/7. Late Capitalism and the End of Sleep. Londres y Nueva York: Verso.

Derrida, Jacques. 2006. Decir el acontecimiento, ¿es posible? Madrid: Arena Libros.

Dolar, Mladen. 2006. A voice and nothing more. Cambridge: MIT Press.

Eljaiek Rodríguez, Gabriel. 2017. Selva de fantasmas. El gótico en la literatura y el cine latinoamericanos. Bogotá: Editorial Pontificia Universidad Javeriana. Ebook.

Larrosa J. 2007. "El rostro enigmático de la infancia". En Miradas cinematográficas de la infancia- Niños atravesando el paisaje, Jorge Larrosa, Inês Assunção de Castro, José de Sousa (eds.), 17-24. Buenos Aires: Miño y Dávila.

Lehmann, H. 2013. Teatro posdramático. Murcia: Centro de Documentación y Estudios Avanzados en Arte Contemporáneo.

Metz, Christian. 1971. "El decir y lo dicho en el cine. ¿Hacia la decadencia de lo verosímil?”. Problemas del nuevo cine, 42-60. Madrid: Alianza Editorial.

Michaux, Henri. 2015. Una vía para la insubordinación. Barcelona: Alpha Decay.

Mistral, Gabriela. 1926. "Menos cóndor y más huemul”. El Mercurio, 11 de julio de 1926. Página 5. Rollo MS164d. Biblioteca Nacional de Chile.

Seel Martin. 2007. Un paso al interior de la estética. Estudios de Filosofía, No $.36 .117-$ 132.

Tsukame, Sáez. 2017. Jóvenes desacreditados. Ideologías y estrategias de control de la delincuencia juvenil en el neoliberalismo chileno (1990-2015). Santiago: Universidad Academia Ediciones. Ebook. 